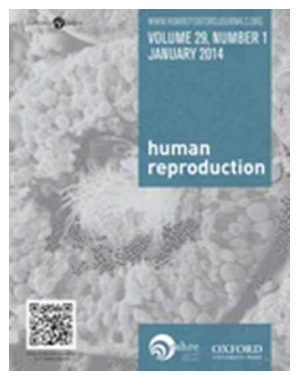

Draft Manuscript For Review. Reviewers should submit their review at http://mc.manuscriptcentral.com/humrep

\title{
External validation of a dynamic prediction model for repeated predictions of natural conception over time
}

\begin{tabular}{|c|c|}
\hline Journal: & Human Reproduction \\
\hline Manuscript ID & HUMREP-18-0188.R1 \\
\hline Manuscript Type: & Original Article \\
\hline Date Submitted by the Author: & 25-Sep-2018 \\
\hline Complete List of Authors: & $\begin{array}{l}\text { van Eekelen, Rik; Amsterdam UMC, Academic Medical Center, Centre for } \\
\text { Reproductive Medicine; University Medical Center Utrecht, Department of } \\
\text { Biostatistics and Research Support, Julius Center } \\
\text { McLernon, David; University of Aberdeen, Medical Statistics Team, Institute } \\
\text { of Applied Health Sciences } \\
\text { van Wely, Madelon; Amsterdam UMC, Amsterdam Medical Center, Centre } \\
\text { for Reproductive Medicine } \\
\text { Eijkemans, Marinus; University Medical Center Utrecht, Department of } \\
\text { Biostatistics and Research Support, Julius Center } \\
\text { Bhattacharya, Siladitya; University of Aberdeen, Institute of Applied Health } \\
\text { Sciences } \\
\text { van der Veen, Fulco; Amsterdam UMC, Academic Medical Center, Centre } \\
\text { for Reproductive Medicine } \\
\text { van Geloven, Nan; Leiden University Medical Center, Medical Statistics, } \\
\text { Department of Biomedical Data Sciences }\end{array}$ \\
\hline Keywords: & $\begin{array}{l}\text { Natural conception, Expectant management, Prognosis, Prediction model, } \\
\text { Dynamic prediction }\end{array}$ \\
\hline Subject Section: & Infertility \\
\hline
\end{tabular}

\section{SCHOLARONE ${ }^{\text {M }}$}




\section{External validation of a dynamic prediction model for}

2 repeated predictions of natural conception over time

3 van Eekelen $\mathrm{R}^{1^{*}, 2}$, McLernon $\mathrm{DJ}^{3}$, van Wely $\mathbf{M}^{1}$, Eijkemans $\mathrm{MJ}^{2}$, Bhattacharya $\mathrm{S}^{4}$, van

4 der Veen $\mathbf{F}^{1}$, van Geloven $\mathbf{N}^{5}$

5

$6{ }^{1}$ Centre for Reproductive Medicine, Amsterdam UMC, Academic Medical Centre,

7 Meibergdreef 91105 AZ Amsterdam, the Netherlands

$8{ }^{2}$ Department of Biostatistics and Research Support, Julius Centre, University Medical Centre

9 Utrecht, Heidelberglaan 100, 3584 CX Utrecht, the Netherlands

$10{ }^{3}$ Medical Statistics Team, Institute of Applied Health Sciences, University of Aberdeen, AB24

11 3FX Aberdeen, United Kingdom

$12{ }^{4}$ Institute of Applied Health Sciences, University of Aberdeen, AB24 3FX Aberdeen, United

13 Kingdom

$14{ }^{5}$ Medical Statistics, Department of Biomedical Sciences, Leiden University Medical Centre, 15 Einthovenweg 20, 2333 ZC Leiden, the Netherlands

- Correspondence address. Email: r.vaneekelen@amc.uva.nl 
Running title: External validation of a dynamic prediction model

Abstract

21

STUDY QUESTION: How well does a previously developed dynamic prediction model perform in an external, geographical validation in terms of predicting the chances of natural conception at various points in time?

on a Scottish cohort.

PARTICIPANTS/MATERIALS, SETTING, METHODS: The endpoint was time to natural conception, leading to an ongoing pregnancy (defined as reaching a gestational age of at least 12 weeks). Follow up was censored at the start of treatment, at the change of partner or at the end of study (31st of March, 2012). The performance of the van Eekelen model was 
evaluated in terms of calibration and discrimination at various points in time. Additionally, we assessed the clinical utility of the model in terms of the range of the calculated predictions.

MAIN RESULTS AND THE ROLE OF CHANCE: Of a total of 1203 couples with a median follow up of 1 year and 3 months after the fertility workup, 398 (33\%) couples conceived naturally leading to an ongoing pregnancy. Using the dynamic prediction model, the mean probability of natural conception over the course of the first year after the fertility workup was estimated at $25 \%$ (observed: $23 \%$ ). After 0.5 year, 1 year and 1.5 years of expectant management after completion of the fertility workup, the average probability of conceiving naturally over the next year was estimated at 18\% (observed: $15 \%$ ), $14 \%$ (observed: $14 \%$ ) and $12 \%$ (observed: $12 \%$ ).

Calibration plots showed good agreement between predicted chances and the observed fraction of ongoing pregnancy within risk groups. Discrimination was moderate with c statistics similar to those in the internal validation, ranging from 0.60 to 0.64 . The range of predicted chances was sufficiently wide to distinguish between couples having a good and poor prognosis with a minimum of zero at all times and a maximum of $55 \%$ over the first year after the workup, which decreased to maxima of $43 \%$ after 0.5 years, $34 \%$ after 1 year and $29 \%$ after 1.5 years after the fertility workup.

LIMITATIONS, REASONS FOR CAUTION: The model slightly overestimated the chances of conception by approximately 2 to 3 percentage points on group level in the first year post fertility workup and after 0.5 years of expectant management, respectively. This is likely attributable to the fact that the exact dates of completion of the fertility workup for couples were missing and had to be estimated.

WIDER IMPLICATIONS OF THE FINDINGS: The van Eekelen model is a valid and robust tool that is ready to use in clinical practice to counsel couples with unexplained subfertility on 
72 their individualised chances of natural conception at various points in time, notably when

73 couples return to the clinic after a period of unsuccessful expectant management.

74

75 STUDY FUNDING/COMPETING INTEREST(S): This work was supported by a Chief

76 Scientist Office postdoctoral training fellowship in health services research and health of the

77 public research (ref PDF/12/06). There are no conflicts of interest.

79 Keywords

80 Natural conception; expectant management; prognosis; prediction model; dynamic prediction;

81 retrospective cohort 


\section{Introduction}

Approximately $10 \%$ of all couples who wish to have a child do not conceive within the first year of trying (Gnoth et al., 2003; Wang et al., 2003). For approximately half of these couples, no clear barrier for conception can be found during the workup and these couples are considered unexplained subfertile (Aboulghar et al., 2009; Brandes et al., 2010). It is unclear whether these couples should start with ART; firstly, since observational studies report that $18 \%$ to $38 \%$ of unexplained subfertile couples will conceive naturally in the year after the fertility workup (Hunault et al., 2004; van der Steeg et al., 2007; van Eekelen et al., 2017a) and secondly, since there remains uncertainty regarding the effectiveness of ART for unexplained subfertile couples (Pandian et al., 2015; Tjon-Kon-Fat et al., 2016; VeltmanVerhulst et al., 2016; van Eekelen et al., 2017b).

In the absence of clear evidence on the management of unexplained subfertile couples and when to offer ART, an enticing option is to calculate chances of natural conception and to base counselling on this estimated prognosis (van Eekelen et al., 2017b). Fundamental to this approach is to identify couples that are expected to benefit from treatment and those who are not. In clinical practice, this would imply that couples with a good prognosis to conceive naturally are advised to continue to try and become pregnant by sexual intercourse, while couples with an unfavourable prognosis are advised to start ART. Several prediction models for natural conception have been published of which the model by Hunault et al., that calculates a prognosis of conception leading to live birth over the first year after completion of the fertility workup, has been externally validated and subsequently implemented in the national guidelines and clinical practice in the Netherlands (Hunault et al., 2004; van der Steeg et al., 2007; Leushuis et al., 2009; NVOG, 2010). A practical drawback of the Hunault model is that it cannot give a prediction at later time points when couples who continued expectant management after the fertility workup but did not conceive, return to the clinic. This is because applying the Hunault model at later time points leads to overestimation due to the selection of less fertile couples over time that is not incorporated in the Hunault model (van Eekelen et al., 2017b). 
Van Eekelen et al. recently developed a dynamic prediction model that accommodates the need for repeated predictions (van Eekelen et al., 2017a). This model comprises the clinical factors female age, duration of subfertility (both at completion of the fertility workup), percentage of progressively motile sperm, primary or secondary subfertility and being referred to the fertility clinic by a general practitioner or a specialist. In addition to these factors, the model uses as input the number of menstrual cycles that have passed since completion of the fertility workup, with zero cycles denoting the prediction is made immediately after the workup. The output is the predicted probability to conceive naturally in the following cycle, leading to ongoing pregnancy, which can be extended to predict over any given number of cycles with a maximum of 2.5 years after the workup (approximately 28-34 cycles). When couples return after a period of expectant management, the number of cycles that have passed since the workup can be changed to update the predicted probability over subsequent cycles.

The model developed by van Eekelen et al. showed promising results in the internal validation, but this in itself is insufficient to advise clinical implementation since models tend to perform better in the cohort they were developed on than in another cohort in which the model may be applied (Steyerberg, 2009).

The aim of this study was to externally validate the van Eekelen model on a large cohort that followed couples for natural conception after registration in the fertility clinic of the Grampian region of Scotland, UK. This is the largest contemporary cohort following couples for natural conception, aside from the Dutch cohort on which the dynamic model was developed.

\section{Materials and Methods}

We included couples diagnosed with unexplained subfertility residing in the Grampian region of Scotland who registered with the Aberdeen Fertility Centre (AFC) from 1998 to 2011 (Pandey et al., 2014). Only patients from the Grampian region visiting the AFC were selected because there is no other fertility clinic in the region and it was considered important to have 
a complete overview of a couple's trajectory after the fertility workup, which includes treatment information. We combined the AFC registration database with three other data sources using record-linkage to get the complete follow up for couples from the registration at the AFC until ongoing pregnancy, treatment or end of study, which was the 31st of March, 2012.

The AFC database comprises patient characteristics and diagnostic information. Data entry in the AFC database is validated and checked by regular case note audits. First, we recordlinked couples registered in the AFC database to the centre's Assisted Reproduction Unit database which contained dates when treatment was started.

Second, we identified natural conceptions leading to an ongoing pregnancy by record-linkage of the AFC database with the Aberdeen Maternity and Neonatal Databank, which contained gestational age, outcome and delivery date of (early) pregnancies for all women residing in Aberdeen City District. Third, we performed record-linkage with the national Scottish Morbidity Records Maternity database for identifying gestational age, outcome and delivery date of (early) pregnancies for women who delivered elsewhere in Scotland.

The Data Management Team of the University of Aberdeen created a new pseudonomised identifier for all women by using the Community Health Index identifier. This new studyspecific identifier cannot be used to trace back to individuals and was then used by author DJM to record-link the databases within the Grampian Data Safe Haven environment. This process was carried out according to the Standard Operating Procedures of the Data Management Team, University of Aberdeen. The resulting linked dataset was thus a combination of these four data sources.

Ethical approval was provided by the North of Scotland Research Ethics Committee (reference: 12/NS/0120). Access to the Aberdeen Fertility Clinic and the Assisted Reproduction Unit databases was approved by the Aberdeen Fertility Databases Steering Committee. Access to the Aberdeen Maternity and Neonatal Databank was approved by the Aberdeen Maternity and Neonatal Database Steering Committee. Access to the Scottish 
Morbidity Records Maternity database was approved by the Privacy Advisory Committee of Information Services Division Scotland.

We defined unexplained subfertility as couples who tried to conceive for more than 50 weeks before the fertility workup was completed and who had no obvious barriers to conception in terms of uni- or bilateral tubal occlusion, anovulation, mild- or severe endometriosis according to the revised American Society for Reproductive Medicine (ASRM) score (ASRM, 1997) or impaired semen quality according to World Health Organization (WHO) criteria (WHO, 1999; WHO, 2010). We used the gestational age at birth or early pregnancy outcome to derive the date of conception and included only pregnancies in the analysis that occurred after registration of the couple at the clinic and that were ongoing, defined as reaching a gestational age of at least 12 weeks. Time to conception was censored at the date of start of IUI, start of IVF, when the woman returned to the fertility centre with a different male partner or at the end of study.

\section{Missing data}

The date of completion of the fertility workup was not reported in the AFC database. The van Eekelen model uses this date as the starting point of follow up, i.e. the time point from which onwards the model can be used to estimate a prognosis. The date of registration and the diagnosis category were available in the database. Judging from local protocols, we assumed there were 3 months in between registration and completion of the fertility workup for all couples. In a sensitivity analysis, we repeated the validation study assuming 1.5 months or 4.5 months between registration and completion of the fertility workup for all couples.

Menstrual cycle length is used to determine the number of elapsed menstrual cycles since the fertility workup when updating predictions using the dynamic prediction model. Cycle length was not recorded in the AFC database and we therefore assumed an average cycle length of 28 days for all women. 
192

193

194

195

196

Data on outcomes or at least one prognostic factor were missing for approximately $4 \%$ of couples; $0.5 \%$ on pregnancy or follow up, $0.5 \%$ on female age, $2.3 \%$ on duration of subfertility, $0.5 \%$ on primary or secondary subfertility, $1.9 \%$ on the percentage of progressive motile sperm and $0.5 \%$ on referral status. We had no reason to believe that couples with missing data differed systematically from couples with complete data and we analysed couples for which data was complete.

\section{Analysis}

We calculated the predicted probabilities of natural conception over 1 year for all couples in the validation cohort using the formula in the Appendix of the paper by van Eekelen et al (van Eekelen et al., 2017a). To test the model's ability to not only predict after the completion of the fertility workup, but also when a couple returns after an unsuccessful period of expectant management, we calculated the prognosis at four time points: directly after completion of the workup, after 0.5 year, 1 year and after 1.5 years of expectant management. We evaluated model performance in terms of calibration, i.e. the degree of agreement between observed and predicted natural conception rates, and discrimination, i.e. the ability of the dynamic prediction model to distinguish between couples who do conceive and couples who do not conceive.

To assess calibration, we first explored whether the overall prediction of the model was correct by comparing the average predicted probability over a time period with the observed conception rate over that same time period. This is referred to as calibration-in-the-large and assesses whether the model systematically under- or overestimates the observed conception rate (Steyerberg, 2009).

Second, we assessed whether the effects of patient characteristics were estimated correctly in three ways: by visuals using calibration plots for risk groups, by calibration within groups with similar patient characteristics and by calculating a calibration slope. For the calibration plots we ordered the predicted probabilities of couples and divided them in risk 
groups with similar predictions ( $n=135$ per risk group). We compared the mean predicted chances within these groups with the corresponding observed fraction of ongoing pregnancy as estimated by the Kaplan-Meier method. We visualized the observed fractions and predicted probabilities per risk group in plots and tabulated the absolute differences. In the plots, the 45 degree line indicates what would be a perfect agreement between the observed fraction and average predicted probability within a risk group.

We repeated the calibration procedure but instead of grouping based on predicted risks, we grouped couples based on having similar patient characteristics. We again compared the mean predicted chances within these groups with the corresponding observed fraction of ongoing pregnancy as estimated by the Kaplan-Meier method and tabulated the results. To calculate the calibration slope, we used the prognostic index (i.e. the sum of the multiplication between all patient characteristics and the coefficients from the model) as an explanatory variable in a Cox model for each of the four evaluated time periods (van Houwelingen, 2000). Ideally, the calibration slope is unity i.e. 1, indicating that the strength of the patient characteristics in the evaluated model perfectly matches the validation data.

Third, we used a recalibration procedure as an alternative way to assess the systematic under- or overestimation (calibration-in-the-large) and the strength of the patient characteristics (calibration slope) in the model. We did this by using the same coefficients for the patient characteristics as reported by van Eekelen et al. to calculate a prognostic index, but re-estimated the other parameters of the beta-geometric model in the validation dataset (Bongaarts, 1975; Weinberg and Gladen, 1986). The recalibration model re-estimates three parameters, which we compared to those in the van Eekelen model and tested for the difference between the two using independent samples z-tests. Systematic under- or overestimation was assessed by comparing the intercept and the variance parameters. The intercept parameter indicates the estimated pregnancy chances in the first cycle after the fertility workup and the variance parameter indicates how fast the estimated chances decrease over consecutive failed natural cycles. Similarity in strength of the patient 
247 characteristics was assessed by again calculating a calibration slope parameter, which would 248 ideally be 1.

We assessed discrimination by calculating Harrel's c statistic at the four time points, which we compared to those found at internal validation (Harrell et al., 1996).

Finally, we explored the range of predicted probabilities at the four time points to see if they facilitate meaningful prognostic stratification of couples (Coppus et al., 2009).

All analyses were conducted in $R$ version 3.4.3 and RStudio ( $R$ Core Team, 2013). A p value below 0.05 was considered statistically significant.

\section{Results}

Data of 1203 couples were included (Fig. 1). The baseline characteristics of the couples are shown in Table I.

In total, 398 (33\%) couples conceived naturally, leading to an ongoing pregnancy. The median follow up was 1 year and 3 months after completion of the workup (average follow up 2 years and 6 months). The observed rates of natural conception up to 2.5 years are depicted in Fig. 2 (upper panel). For couples who did not yet conceive after 0.5 year, 1 year or 1.5 years after completion of the fertility workup, the observed rates of natural conception over the following year are depicted in Fig. 2 (lower panel). The mean probability of natural conception as predicted by the dynamic model over the course of the first year after the fertility workup was $25 \%$ while the observed fraction was $23 \%(95 \% \mathrm{Cl} 20-25)$. For couples who did not conceive after 0.5 years, after 1 year and after 1.5 years of expectant management, the mean estimated probability of conceiving over the course of the following

271 year was estimated at $18 \%, 14 \%$ and $12 \%$. The observed rates were $15 \%(13-18 \%), 14 \%$

$272(11-17 \%)$ and $12 \%(9-15 \%)$ for these three time periods, respectively (Fig. 2, lower panel).

273 Except for the second period during which the model slightly overestimated the pregnancy chances by 3 percentage points, the mean predicted probabilities fell within their respective 
confidence limits of the observed rates, indicating good agreement between the average prediction rendered by the dynamic model and the corresponding observed rate of natural conception.

The calibration plots for the four time periods are presented in Fig. 3. The dynamic prediction model was well calibrated based on the upward trends observed in the four plots, indicating that higher predicted probabilities correspond to higher observed rates, and the Cls from the observed rates which all but one cover the ideal 45 degree line. The second calibration plot starting at 0.5 years after the fertility workup showed a slight overestimation since all points are below the 45 degree line. The absolute differences between observed fractions and predicted probabilities of natural conception within risk groups are shown in Table II. This was on average 2.8 percentage points and 9.6 at the highest.

The results for the calibration grouping couples by similar characteristics are shown in Supplementary Data I. Results were similar to those in the calibration using risk groups, with a slight overestimation in the time periods right after completion of the fertility workup and after 0.5 years of expectant management.

The calibration slopes using Cox models were $0.86,1.01,1.01$ and 0.62 for the four time periods, respectively. None of the corresponding $p$-values were below 0.05 , indicating no statistical evidence for under- or overfitting.

In the recalibration model, the intercept and variance parameters were similar to those reported by van Eekelen et al. ( $p=0.69$ and $p=0.29$ for the difference, respectively), indicating similar underlying chances of pregnancy in the first cycle after the workup and a similar decrease in chances as time progresses. The slope was $0.90(p=0.37)$, indicating a similar strength of patient characteristics in the validation cohort and no significant difference from 1.

The discriminative ability of the model in the validation cohort was moderate and similar to that in the Dutch development cohort, ranging over time from a c statistic of $0.61(95 \% \mathrm{Cl}$ $0.57-0.64)$ in the first year, $0.62(95 \% \mathrm{Cl} 0.58-0.67)$ from 0.5 years, $0.63(95 \% \mathrm{Cl} 0.57-0.69)$ 
303

304

305

306

307

308

309

310

311

312

313

314

315

316

317

318

319

320

321

322

323

324

325

326

327

328

329

330

from 1 year, to $0.60(95 \% \mathrm{Cl} 0.52-0.67)$ for 1.5 years after completion of the fertility workup, all for conceiving in the following year. The c statistics were around 0.61 for all four time periods and seemed stable over time.

The range of predictions varied between 0 and $55 \%$ over the course of the first year after the fertility workup. After 0.5 years, 1 year and 1.5 years of expectant management the ranges narrowed to 0 to $43 \%, 0$ to $34 \%$ and 0 to $29 \%$ respectively, all over the course of the following year, facilitating a distinction between couples with a good or poor prognosis.

\section{Sensitivity analyses}

Results from the two sensitivity analyses are reported online as supplementary data. The analysis where we assumed 1.5 months between registration and completion of the fertility workup showed a very good performance of the dynamic prediction model (Supplementary Table SI, Supplementary Figs. S1 and S2). The analysis assuming 4.5 months between registration and completion of the fertility workup showed similar results to the primary analysis but with slightly more overestimation of chances by the model (Supplementary Table SII, Supplementary Figs. S3 and S4).

\section{Discussion}

We conducted an external, geographical validation of the van Eekelen model that can be used for repeated predictions of natural conception when couples return to the clinic after unsuccessful expectant management. The model performed well in a Scottish cohort of couples with unexplained subfertility that visited a fertility clinic and the model is expected to be generalizable to other fertility centres and countries where the procedure of managing unexplained subfertile couples is comparable to the Netherlands and the UK. In addition, the predicted probabilities varied sufficiently to aid in distinguishing between couples with a good and poor prognosis in terms of natural conception. 
The data from the AFC was of high quality, registering every unexplained subfertile couple in the Grampian region. All natural conceptions leading to ongoing pregnancy, including after miscarriages and other early pregnancy outcomes, were found using data linkage with maternity records. Indications for the fertility workup and definitions of censoring and prognostic characteristics in the Scottish cohort were very similar to the Dutch cohort, aiding comparability (van Eekelen et al., 2017a).

The model was well calibrated, which we consider of higher importance than discrimination since the $c$ statistic can be expected to be moderate due to the limited range of predicted chances in fertility (Mol et al., 2005; Cook, 2007). This restricts the maximum possible c statistic, even if a model were to produce perfect predictions. Recalibration, in which one or more parameters of the prediction model are updated to accommodate better predictions in a different country or clinical setting, was not necessary since the recalibration model showed similar values for all parameters as observed in the development cohort.

The main limitation to our study was missing data in terms of dates of completion of the fertility workup and menstrual cycle lengths. Menstrual cycle length was not considered very influential since the estimations of the number of cycles per individual are reasonable approximations due to the narrow range of possible cycle lengths in our selection of unexplained subfertile couples, but we did have to make strong assumptions about the date of completion of the fertility workup. We assumed 3 months between registration and completion of the fertility workup, which resulted in ongoing pregnancies before 3 months after registration being excluded. The 'starting' moment of follow up thus differed from the Dutch development cohort since in the latter, the date of last tubal test was used as the end of the workup. Some Dutch clinics did not conduct a visual test of tubal patency, i.e. laparoscopy or hysterosalpingography after a negative result for the chlamydia antibody test. In those Dutch clinics, the workup was thus considered as complete earlier after registration compared to the AFC where visual tests of tubal patency are part of the standard protocol. 
This may have led to the observed slight overestimation in the first year after the fertility workup and after 0.5 years of expectant management but, despite these differences, the dynamic model was still able to estimate a prognosis that was reasonably accurate on cohort and risk group level. The results from the sensitivity analysis assuming 1.5 months between registration and completion of the fertility workup were very good because the resulting population more closely resembled that of the Dutch development cohort in which the same average duration was observed between registration and the workup completion.

Accordingly, in the analysis assuming 4.5 months between registration and completion of the fertility workup, the performance of the dynamic model was poorer because the populations differed more due to additional selection that occurred.

The dynamic model is able to reassess the chance of natural conception after any given period of expectant management from the completion of the fertility workup onwards. For example, a couple with 1 year secondary subfertility is referred by a general practitioner to the fertility clinic of which the woman is 33 years old at the completion of the fertility workup and the man has $40 \%$ progressive motile sperm. Applying our model gives a predicted $38 \%$ chance of natural conception over the first year after the workup and they might be advised expectant management. When the couple returns to the clinic after 10 unsuccessful months/cycles, reapplying the model yields $25 \%$ chance over the following year, which is a realistic decrease given they have tried for an additional 10 months. This could be a reason to consider starting treatment.

Both the Hunault model and the dynamic model performed well in external validations, indicating that the added value of the dynamic model lies in the ability to update predictions at later time points (van Eekelen et al., 2017a). This provides clinicians and patients with information regarding their prognosis of natural conception not only right after completion of the fertility workup, but also when the couple returns after an additional, unsuccessful period of expectant management, thus aiding in making clinical decisions at multiple time points 
387 throughout a couple's trajectory. The ability to update predictions also aids in studies which 388 include the prognosis of natural conception as an in- or exclusion criterion, since the 389 prognosis of couples who return after unsuccessful expectant management can be updated

390

391

392

393

394

395

396

397

398

399

400

401 accurately, leading to the desired homogeneity of the study sample (van den Boogaard et al., 2014). The dynamic model is flexible and can be used to predict over any desired number of menstrual cycles, for instance when the couple is interested in time periods shorter or longer than 1 year. In short, the dynamic model has a wider clinical applicability than the Hunault model and should be the model of choice.

\section{Conclusion}

The van Eekelen model is a valid and robust tool that is ready to use in clinical practice to counsel couples with unexplained subfertility on their individualised chances of natural conception at various points in time, notably when couples return to the clinic after a period of unsuccessful expectant management. 
402

403

404

405

406

407

408

409

410

411

412

413

414

415

416

417

418

419

420

421

422

423

424

425

426

427

428

429

\section{Supplementary data}

Supplementary data are available at Human Reproduction online.

\section{Acknowledgements}

The authors would like to thank Prof. Egbert te Velde for all of his efforts regarding development of the dynamic prediction model and the current validation study.

We acknowledge the data management support of the Grampian Data Safe Haven (DaSH) and the associated financial support of NHS Research Scotland, through NHS Grampian investment in the Grampian DaSH. For more information, visit the DaSH website http://www.abdn.ac.uk/iahs/facilities/grampian-data-safe-haven.php.

We would like to thank all the staff at Aberdeen Fertility Clinic for their help with database queries.

\section{Authors' roles}

NvG, MDJ, BS, FvdV, MvW and MJE conceived the study. MDJ performed the data linkage, storage in the Safe Haven and cleaned the data. RvE, NvG and MJE designed the statistical analysis plan. RvE, MDJ and NvG analysed the data. RvE drafted the manuscript. All authors contributed critical revision to the paper and approved the final manuscript.

\section{Funding}

This work was supported by a Chief Scientist Office postdoctoral training fellowship in health services research and health of the public research (ref PDF/12/06). The views expressed here are those of the authors and not necessarily those of the Chief Scientist Office. The funder did not have any role in the study design; the collection, analysis, and interpretation of data; the writing of the report; nor the decision to submit the paper for publication.

\section{Conflicts of interest}

None. 
431

432

433

434

435

436

437

438

439

440

441

442

443

444

445

446

447

448

449

450

451

452

453

454

455

456

\section{References}

Aboulghar M, Baird D, Collin J, Evers J, Fauser B, Lambalk C and Other A. Intrauterine insemination. Hum Reprod Update 2009;15:265-277.

ASRM. Revised American Society for Reproductive Medicine classification of endometriosis: 1996. Fertil Steril 1997;67:817-821.

Bongaarts J. A method for the estimation of fecundability. Demography 1975;12:645-660.

Brandes M, Hamilton CJ, de Bruin JP, Nelen WL and Kremer JA. The relative contribution of IVF to the total ongoing pregnancy rate in a subfertile cohort. Hum Reprod 2010;25:118-126.

Cook NR. Use and misuse of the receiver operating characteristic curve in risk prediction. Circulation 2007;115:928-935.

Coppus SF, van der Veen F, Opmeer BC, Mol BW and Bossuyt PM. Evaluating prediction models in reproductive medicine. Hum Reprod 2009;24:1774-1778.

Gnoth C, Godehardt D, Godehardt E, Frank-Herrmann P and Freundl G. Time to pregnancy: results of the German prospective study and impact on the management of infertility. Hum Reprod 2003;18:1959-1966.

Harrell FE, Jr., Lee KL and Mark DB. Multivariable prognostic models: issues in developing models, evaluating assumptions and adequacy, and measuring and reducing errors. Stat Med 1996;15:361-387. 
460

461

462

463

464

465

466

467

468

469

470

471

472

473

474

475

476

477

478

479

480

481

482

483

Hunault CC, Habbema JD, Eijkemans MJ, Collins JA, Evers JL and te Velde ER. Two new prediction rules for spontaneous pregnancy leading to live birth among subfertile couples, based on the synthesis of three previous models. Hum Reprod 2004;19:2019-2026.

Leushuis E, van der Steeg JW, Steures P, Bossuyt PM, Eijkemans MJ, van der Veen F, Mol BW and Hompes PG. Prediction models in reproductive medicine: a critical appraisal. Hum Reprod Update 2009;15:537-552.

Mol BW, Coppus SF, Van der Veen F and Bossuyt P. ROC-curves are misleading; calibration is not! Fertil Steril 2005;84:253-254.

NVOG, Dutch Society for Obstetrics and Gynaecology. Guideline on: subfertility (2010).

Accessed on: 5th of February, 2017. Available from: http://bit.ly/1UhuYMV.

Pandey S, McLernon DJ, Scotland G, Mollison J, Wordsworth S and Bhattacharya S. Cost of fertility treatment and live birth outcome in women of different ages and BMI. Hum Reprod 2014;29:2199-2211.

Pandian Z, Gibreel A and Bhattacharya S. In vitro fertilisation for unexplained subfertility. Cochrane Database Syst Rev 2015;Cd003357.

R Core Team (2013). R: A language and environment for statistical computing. R Foundation for Statistical Computing, Vienna, Austria. http://www.R-project.org/.

Steyerberg E. Clinical Prediction Models: A Practical Approach to Development, Validation and Updating. Springer 2009. 
484 Tjon-Kon-Fat RI, Bensdorp AJ, Scholten I, Repping S, van Wely M, Mol BW and van der

485 Veen F. IUI and IVF for unexplained subfertility: where did we go wrong? Hum Reprod $486 \quad 2016 ; 31: 2665-2667$.

487

van den Boogaard NM, Bensdorp AJ, Oude Rengerink K, Barnhart K, Bhattacharya S,

Custers IM, Coutifaris C, Goverde AJ, Guzick DS, Hughes EC, et al. Prognostic profiles and the effectiveness of assisted conception: secondary analyses of individual patient data. Hum Reprod Update 2014;20:141-151.

492

a. van Eekelen R, Scholten I, Tjon-Kon-Fat RI, van der Steeg JW, Steures P, Hompes P, van Wely M, van der Veen F, Mol BW, Eijkemans MJ, et al. Natural conception: repeated predictions over time. Hum Reprod 2017a;32:346-353.

496

b. van Eekelen R, van Geloven N, van Wely M, McLernon DJ, Eijkemans MJ, Repping S, Steyerberg EW, Mol BW, Bhattacharya S and van der Veen F. Constructing the crystal ball: how to get reliable prognostic information for the management of subfertile couples. Hum Reprod 2017b;32:2153-2158.

501

van Houwelingen HC. Validation, calibration, revision and combination of prognostic survival models. Stat Med 2000;19:3401-3415.

504

van der Steeg JW, Steures P, Eijkemans MJ, Habbema JD, Hompes PG, Broekmans FJ, van Dessel HJ, Bossuyt PM, van der Veen F and Mol BW. Pregnancy is predictable: a large507 scale prospective external validation of the prediction of spontaneous pregnancy in subfertile couples. Hum Reprod 2007;22:536-542. unexplained subfertility. Cochrane Database Syst Rev 2016;2:Cd001838. 
513 Wang X, Chen C, Wang L, Chen D, Guang W and French J. Conception, early pregnancy

514 loss, and time to clinical pregnancy: a population-based prospective study. Fertil Steril

$515 \quad 2003 ; 79: 577-584$.

516

517 Weinberg CR and Gladen BC. The beta-geometric distribution applied to comparative

518 fecundability studies. Biometrics 1986;42:547-560.

519

520

WHO, World Health Organization. Laboratory Manual for the Examination of Human Semen

521 and Sperm-Cervical Mucus Interaction. 4th edn 1999. Cambridge University Press,

Cambridge.

523

524

WHO, World Health Organisation. Laboratory Manual for the Examination and Processing of Human Semen, 5th ed 2010. Geneva: World Health Organization.

\section{FIGURE LEGENDS}

Figure 1 Flow chart of couples with unexplained subfertility who were considered for inclusion in the external validation.

531

Figure 2 Cumulative chances of natural conception leading to ongoing pregnancy. years, 1 year and 1.5 years thereafter (lower panel) in the validation cohort. leading to ongoing pregnancy. 
Figure 3 Calibration of the predictions of the dynamic prediction model: predicted versus observed 1 year natural conception rates at four fixed time points.

Supplementary Figure S1 Cumulative chances of natural conception leading to ongoing pregnancy after completion of fertility workup (upper panel) and updated chances of natural conception over the course of 1 year at completion of the fertility workup or 0.5 years, 1 year and 1.5 years thereafter (lower panel) in the validation cohort. Percentages are Kaplan-Meier estimates of the observed fraction of natural conception leading to ongoing pregnancy. Data analysis assumed 1.5 months between registration at the Aberdeen Fertility Clinic and completion of the fertility workup ( $n=1261)$.

Supplementary Figure S2 Calibration of the predictions of the dynamic prediction model: predicted versus observed 1 year natural conception rates at four fixed time points. Data analysis assumed 1.5 months between registration at the Aberdeen Fertility Clinic and completion of the fertility workup $(n=1261)$.

\section{Supplementary Figure S3 Cumulative chances of natural conception leading to ongoing} pregnancy after completion of fertility workup (upper panel) and updated chances of natural conception over the course of 1 year at completion of the fertility workup or 0.5 years, 1 year and 1.5 years thereafter (lower panel) in the validation cohort. Percentages are Kaplan-Meier estimates of the observed fraction of natural conception leading to ongoing pregnancy. Data analysis assumed 4.5 months between registration at the Aberdeen Fertility Clinic and completion of the fertility workup $(n=1123)$.

Supplementary Figure S4 Calibration of the predictions of the dynamic prediction model: predicted versus observed 1 year natural conception rates at four fixed time points. Data 
566 analysis assumed 4.5 months between registration at the Aberdeen Fertility Clinic and 567 completion of the fertility workup $(n=1123)$. 


\section{Figure 1.}

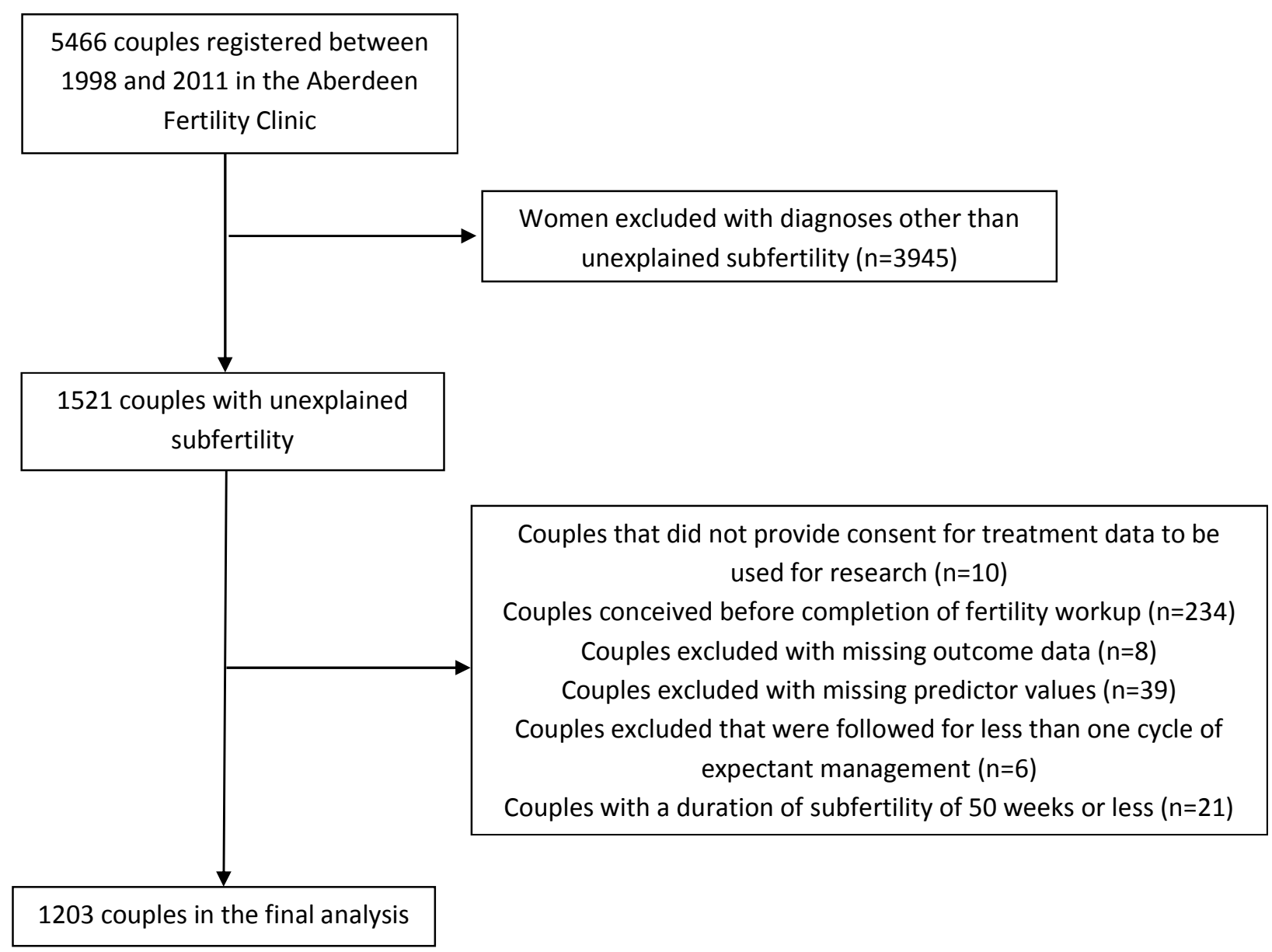




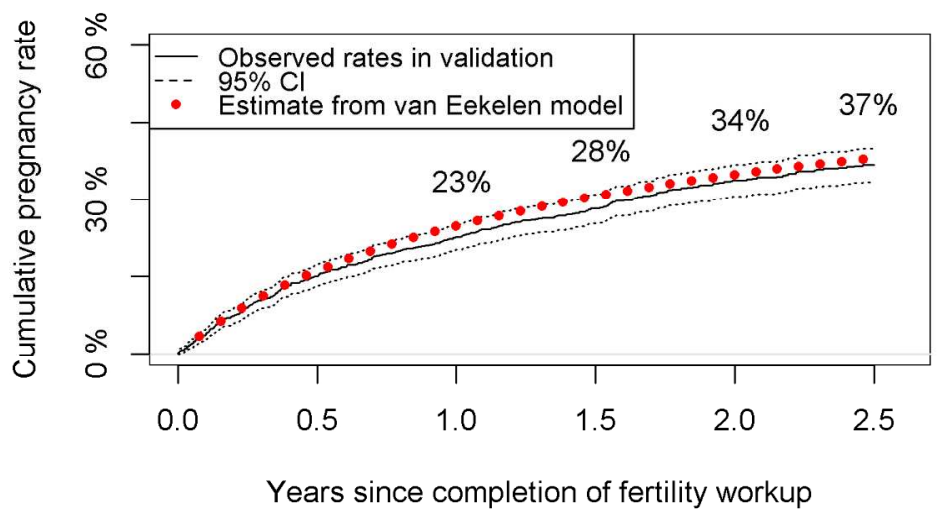

$\begin{array}{llllll}n \text { in follow up } & 1203 & 925 & 703 & 514 & 403\end{array}$

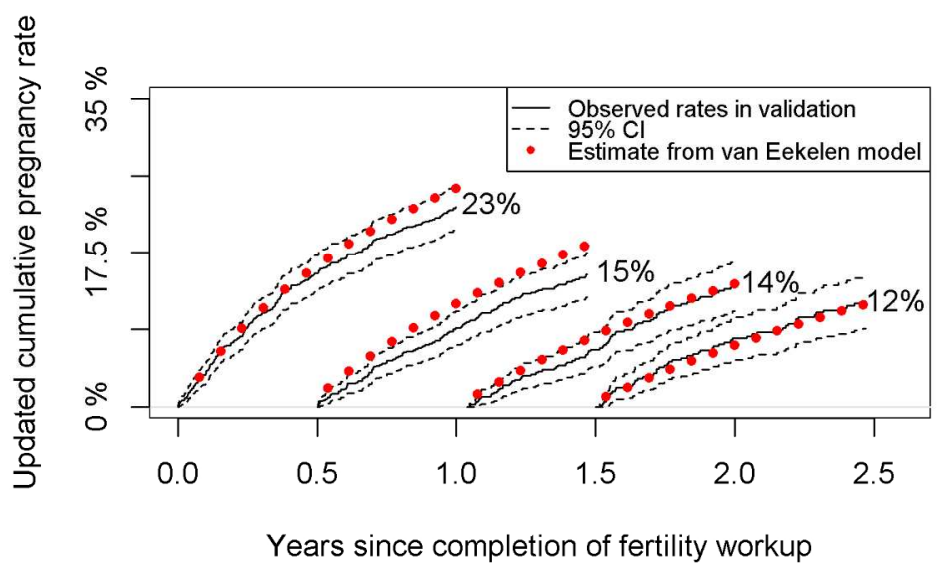

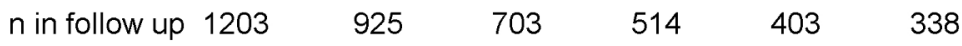

$160 \times 220 \mathrm{~mm}(300 \times 300 \mathrm{DPI})$ 

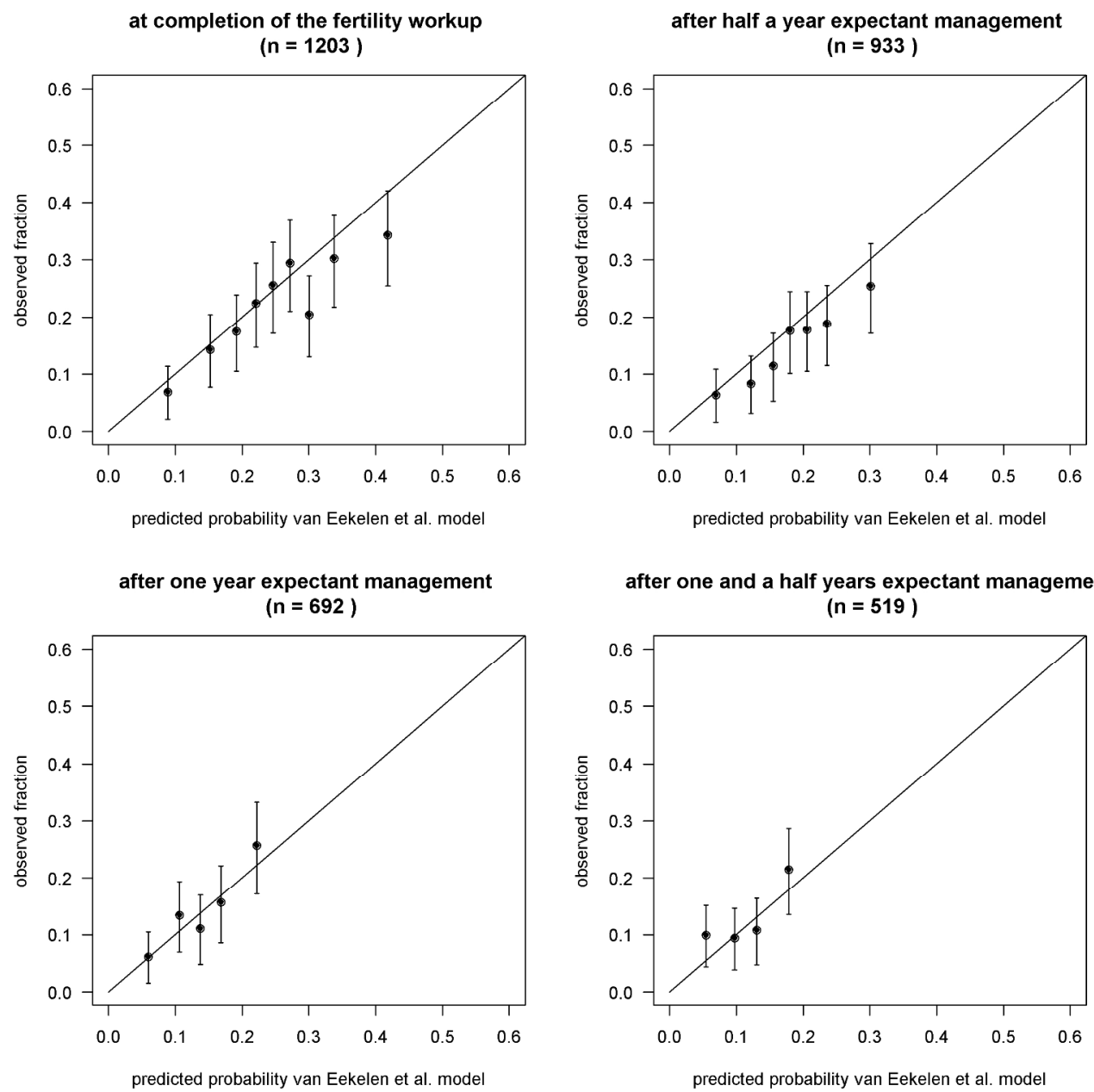

after one and a half years expectant management $(n=519)$

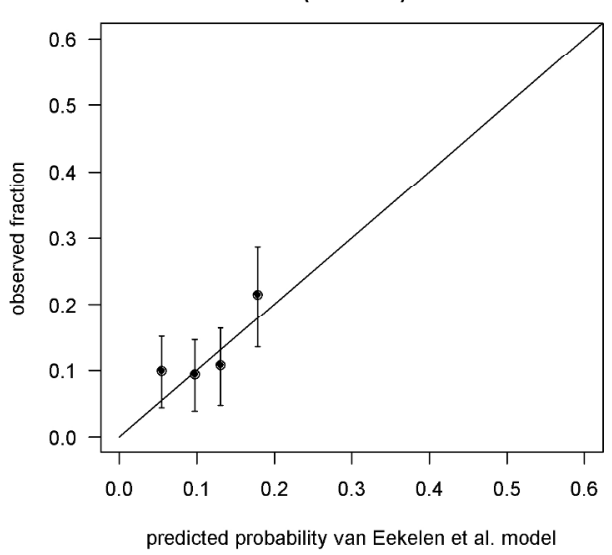

$228 \times 228 \mathrm{~mm}(300 \times 300 \mathrm{DPI})$ 
Table I Baseline characteristics at completion of the fertility workup.

$n=1203$

Female age, in years

Duration of subfertility, in years

Primary female subfertility

Percentage of progressive motile sperm

Referral by secondary care
Mean or $\mathbf{n}$

2.7

697

51

84
5 th $-95^{\text {th }}$

percentile or $\%$

$25-41$

$1.3-5.6$

$58 \%$

$24-76$

$7 \%$

Table II Calibration of the dynamic prediction model by risk groups.

\section{Mean difference Max difference Number of risk groups}

After completion of workup

After 0.5 year EM

After 1 year EM

After 1.5 years EM
3.2

3.0

2.1

2.7
9.6

4.7

3.5

4.5
9

7

5

4

\section{Total}

2.8

9.6

25

Data are the mean and maximum of the absolute differences (in percentage points) between predicted and observed 1 year natural conception rates per risk group of $n=135$, stratified by the elapsed period of expectant management (EM). 


\section{Supplementary Data}

Calibration per strata of patient characteristics.

Analyses were conducted for all four time periods in the primary scenario with 3 months between registration and completion of fertility workup.

Time period 1: after completion of the fertility workup

Female age:

\begin{tabular}{|c|c|c|}
\hline Category [mean, $\mathbf{n}]$ & $\begin{array}{c}\text { Predicted } \\
\text { probability in \% }\end{array}$ & $\begin{array}{c}\text { Observed fraction } \\
\text { in } \% \mathbf{( 9 5 \% C l )}\end{array}$ \\
\hline & & \\
\hline$<=28$ years $[25.4, \mathrm{n}=155]$ & 33 & $30(22-37)$ \\
\hline $28-32$ years $[29.3, \mathrm{n}=336]$ & 29 & $26(21-30)$ \\
\hline $32-35$ years $[33.2, \mathrm{n}=261]$ & 24 & $23(17-28)$ \\
\hline$>35$ years $[38.3, \mathrm{n}=451]$ & 19 & $18(14-21)$ \\
\hline
\end{tabular}

Duration of subfertility:

\begin{tabular}{|c|c|c|}
\hline Category [mean, $\mathbf{n}]$ & $\begin{array}{c}\text { Predicted } \\
\text { probability in } \%\end{array}$ & $\begin{array}{c}\text { Observed fraction } \\
\text { in } \% \mathbf{~ ( 9 5 \% ~} \mathbf{C l})\end{array}$ \\
\hline & & \\
\hline $1-1.5$ years $[1.3, \mathrm{n}=227]$ & 30 & $26(20-32)$ \\
\hline $1.5-2$ years $[1.8, \mathrm{n}=262]$ & 29 & $26(21-32)$ \\
\hline $2-3$ years $[2.4, \mathrm{n}=393]$ & 25 & $24(20-29)$ \\
\hline$>3$ years $[4.7, \mathrm{n}=321]$ & 16 & $14(10-19)$ \\
\hline
\end{tabular}

Percentage of progressive motile sperm:

\begin{tabular}{|c|c|c|}
\hline Category [mean, $\mathbf{n}]$ & $\begin{array}{c}\text { Predicted } \\
\text { probability in \% }\end{array}$ & $\begin{array}{c}\text { Observed fraction } \\
\text { in \% (95\%Cl) }\end{array}$ \\
\hline & & \\
\hline$<=35 \%[26, \mathrm{n}=220]$ & 21 & $18(13-23)$ \\
\hline $35-50 \%[43, \mathrm{n}=376]$ & 24 & $23(19-28)$ \\
\hline $50-65 \%[58, \mathrm{n}=366]$ & 26 & $23(18-27)$ \\
\hline$>65 \%[73, \mathrm{n}=241]$ & 28 & $26(19-31)$ \\
\hline
\end{tabular}

Primary or secondary subfertility:

\begin{tabular}{|c|c|c|}
\hline Category [n] & $\begin{array}{c}\text { Predicted } \\
\text { probability in \% }\end{array}$ & $\begin{array}{c}\text { Observed fraction } \\
\text { in \% (95\% Cl) }\end{array}$ \\
\hline & & \\
\hline Primary [n=697] & 23 & $20(17-23)$ \\
\hline Secondary [n=506] & 28 & $26(22-30)$ \\
\hline
\end{tabular}

Referral by general practitioner (GP) or specialist/gynaecologist:

\begin{tabular}{|c|c|c|}
\hline Category [n] & $\begin{array}{c}\text { Predicted } \\
\text { probability in \% }\end{array}$ & $\begin{array}{c}\text { Observed fraction } \\
\text { in \% (95\%Cl) }\end{array}$ \\
\hline & & \\
\hline GP [n=1119] & 26 & $23(20-25)$ \\
\hline Specialist/gynaecologist & 13 & $20(10-29)$ \\
\hline
\end{tabular}


[n=84]

Time period 2: after 0.5 years of expectant management

Female age:

\begin{tabular}{|c|c|c|}
\hline Category [mean, $\mathbf{n}]$ & $\begin{array}{c}\text { Predicted } \\
\text { probability in \% }\end{array}$ & $\begin{array}{c}\text { Observed fraction } \\
\text { in } \% \mathbf{~ ( 9 5 \% C l ) ~}\end{array}$ \\
\hline & & \\
\hline$<=28$ years $[25.4, \mathrm{n}=117]$ & 24 & $22(13-29)$ \\
\hline $28-32$ years $[29.9, \mathrm{n}=262]$ & 22 & $18(12-22)$ \\
\hline $32-35$ years $[33.2, \mathrm{n}=205]$ & 17 & $16(11-22)$ \\
\hline$>35$ years $[38.3, \mathrm{n}=349]$ & 14 & $11(7-14)$ \\
\hline
\end{tabular}

Duration of subfertility:

\begin{tabular}{|c|c|c|}
\hline Category [mean, $\mathbf{n}]$ & $\begin{array}{c}\text { Predicted } \\
\text { probability in \% }\end{array}$ & $\begin{array}{c}\text { Observed fraction } \\
\text { in } \%(\mathbf{9 5 \%} \mathbf{C l})\end{array}$ \\
\hline & & \\
\hline $1-1.5$ years $[1.3, \mathrm{n}=170]$ & 23 & $18(12-24)$ \\
\hline $1.5-2$ years $[1.8, \mathrm{n}=204]$ & 22 & $19(13-25)$ \\
\hline $2-3$ years $[2.4, \mathrm{n}=309]$ & 19 & $17(13-22)$ \\
\hline$>3$ years $[4.7, \mathrm{n}=250]$ & 12 & $8(4-11)$ \\
\hline
\end{tabular}

Percentage of progressive motile sperm:

\begin{tabular}{|c|c|c|}
\hline Category [mean, $\mathbf{n}]$ & $\begin{array}{c}\text { Predicted } \\
\text { probability in \% }\end{array}$ & $\begin{array}{c}\text { Observed fraction } \\
\text { in \% (95\% } \mathbf{C l})\end{array}$ \\
\hline & & \\
\hline$<=35 \%[26, \mathrm{n}=176]$ & 15 & $14(8-20)$ \\
\hline $35-50 \%[43, \mathrm{n}=282]$ & 18 & $14(9-18)$ \\
\hline $50-65 \%[58, \mathrm{n}=291]$ & 19 & $16(11-20)$ \\
\hline$>65 \%[73, \mathrm{n}=184]$ & 21 & $18(12-24)$ \\
\hline
\end{tabular}

Primary or secondary subfertility:

\begin{tabular}{|c|c|c|}
\hline Category [n] & $\begin{array}{c}\text { Predicted } \\
\text { probability in \% }\end{array}$ & $\begin{array}{c}\text { Observed fraction } \\
\text { in \% (95\%Cl) }\end{array}$ \\
\hline & & \\
\hline Primary [n=550] & 17 & $14(11-17)$ \\
\hline Secondary [n=383] & 20 & $17(13-21)$ \\
\hline
\end{tabular}

Referral by general practitioner (GP) or specialist/gynaecologist:

\begin{tabular}{|c|c|c|}
\hline Category [n] & $\begin{array}{c}\text { Predicted } \\
\text { probability in } \%\end{array}$ & $\begin{array}{c}\text { Observed fraction } \\
\text { in \% (95\%Cl) }\end{array}$ \\
\hline GP [n=867] & 19 & $15(13-18)$ \\
\hline $\begin{array}{c}\text { Specialist/gynaecologist } \\
{[\mathrm{n}=66]}\end{array}$ & 10 & $14(4-23)$ \\
\hline
\end{tabular}


Time period 3: after 1 year of expectant management

Female age:

\begin{tabular}{|c|c|c|}
\hline Category [mean, $\mathbf{n}]$ & $\begin{array}{c}\text { Predicted } \\
\text { probability in \% }\end{array}$ & $\begin{array}{c}\text { Observed fraction } \\
\text { in \% } \mathbf{( 9 5 \% C l )}\end{array}$ \\
\hline & & \\
\hline$<=28$ years $[25.4, \mathrm{n}=92]$ & 19 & $24(14-34)$ \\
\hline $28-32$ years $[29.9, \mathrm{n}=189]$ & 17 & $19(12-25)$ \\
\hline $32-35$ years $[33.2, \mathrm{n}=154]$ & 14 & $15(8-21)$ \\
\hline$>35$ years $[38.5, \mathrm{n}=257]$ & 10 & $7(4-10)$ \\
\hline
\end{tabular}

Duration of subfertility:

\begin{tabular}{|c|c|c|}
\hline Category [mean, $\mathbf{n}]$ & $\begin{array}{c}\text { Predicted } \\
\text { probability in } \%\end{array}$ & $\begin{array}{c}\text { Observed fraction } \\
\text { in } \% \mathbf{~ ( 9 5 \% C l ) ~}\end{array}$ \\
\hline & & \\
\hline $1-1.5$ years $[1.3, n=129]$ & 18 & $16(9-23$ \\
\hline $1.5-2$ years $[1.8, n=150]$ & 17 & $20(12-27)$ \\
\hline $2-3$ years $[2.4, n=223]$ & 14 & $15(9-20)$ \\
\hline$>3$ years $[4.8, n=190]$ & 9 & $9(5-14)$ \\
\hline
\end{tabular}

Percentage of progressive motile sperm:

\begin{tabular}{|c|c|c|}
\hline Category [mean, $\mathbf{n}]$ & $\begin{array}{c}\text { Predicted } \\
\text { probability in \% }\end{array}$ & $\begin{array}{c}\text { Observed fraction } \\
\text { in \% (95\% } \mathbf{~ C l ) ~}\end{array}$ \\
\hline & & \\
\hline$<=35 \%[26, \mathrm{n}=137]$ & 12 & $16(9-22)$ \\
\hline $35-50 \%[43, \mathrm{n}=208]$ & 14 & $14(8-19)$ \\
\hline $50-65 \%[58, \mathrm{n}=211]$ & 15 & $14(9-19)$ \\
\hline$>65 \%[73, \mathrm{n}=136]$ & 15 & $15(8-21)$ \\
\hline
\end{tabular}

Primary or secondary subfertility:

\begin{tabular}{|c|c|c|}
\hline Category [n] & $\begin{array}{c}\text { Predicted } \\
\text { probability in \% }\end{array}$ & $\begin{array}{c}\text { Observed fraction } \\
\text { in \% (95\%Cl) }\end{array}$ \\
\hline & & \\
\hline Primary $[\mathrm{n}=402]$ & 13 & $15(11-19)$ \\
\hline Secondary $[\mathrm{n}=290]$ & 15 & $13(9-17)$ \\
\hline
\end{tabular}

Referral by general practitioner (GP) or specialist/gynaecologist:

\begin{tabular}{|c|c|c|}
\hline Category [n] & $\begin{array}{c}\text { Predicted } \\
\text { probability in \% }\end{array}$ & $\begin{array}{c}\text { Observed fraction } \\
\text { in \% (95\%Cl) }\end{array}$ \\
\hline GP [n=645] & 14 & $15(12-18)$ \\
\hline $\begin{array}{c}\text { Specialist/gynaecologist } \\
{[\mathrm{n}=47]}\end{array}$ & 7 & $11(1-20)$ \\
\hline
\end{tabular}


Time period 4: after 1.5 years of expectant management

Female age:

\begin{tabular}{|c|c|c|}
\hline Category [mean, $\mathbf{n}]$ & $\begin{array}{c}\text { Predicted } \\
\text { probability in \% }\end{array}$ & $\begin{array}{c}\text { Observed fraction } \\
\text { in \% (95\%Cl) }\end{array}$ \\
\hline & & $21(10-30)$ \\
\hline$<=28$ years $[25.3, \mathrm{n}=69]$ & 16 & $21(13-28)$ \\
\hline $28-32$ years $[29.9, \mathrm{n}=143]$ & 14 & $11(4-17)$ \\
\hline $32-35$ years $[33.2, \mathrm{n}=107]$ & 11 & $6(2-9)$ \\
\hline$>35$ years $[38.8, \mathrm{n}=200]$ & 9 &
\end{tabular}

Duration of subfertility:

\begin{tabular}{|c|c|c|}
\hline Category [mean, $\mathbf{n}]$ & $\begin{array}{c}\text { Predicted } \\
\text { probability in \% }\end{array}$ & $\begin{array}{c}\text { Observed fraction } \\
\text { in } \%(\mathbf{9 5} \% \mathbf{C l})\end{array}$ \\
\hline & & $10(3-16)$ \\
\hline $1-1.5$ years $[1.3, \mathrm{n}=93]$ & 15 & $19(11-26)$ \\
\hline $1.5-2$ years $[1.8, \mathrm{n}=104]$ & 14 & $12(6-17)$ \\
\hline $2-3$ years $[2.4, \mathrm{n}=172]$ & 12 & $12(6-17)$ \\
\hline$>3$ years $[4.8, \mathrm{n}=150]$ & 8 & \\
\hline
\end{tabular}

Percentage of progressive motile sperm:

\begin{tabular}{|c|c|c|}
\hline Category [mean, $\mathbf{n}]$ & $\begin{array}{c}\text { Predicted } \\
\text { probability in \% }\end{array}$ & $\begin{array}{c}\text { Observed fraction } \\
\text { in \% (95\%Cl) }\end{array}$ \\
\hline & & $14(6-21)$ \\
\hline$<=35 \%[25, \mathrm{n}=95]$ & 10 & $13(7-19)$ \\
\hline $35-50 \%[43, \mathrm{n}=161]$ & 12 & $14(8-19)$ \\
\hline $50-65 \%[58, \mathrm{n}=161]$ & 12 & $11(4-17)$ \\
\hline$>65 \%[73, \mathrm{n}=102]$ & 13 & \\
\hline
\end{tabular}

Primary or secondary subfertility:

\begin{tabular}{|c|c|c|}
\hline Category [n] & $\begin{array}{c}\text { Predicted } \\
\text { probability in \% }\end{array}$ & $\begin{array}{c}\text { Observed fraction } \\
\text { in \% (95\% } \mathbf{~} \mathbf{\text { }})\end{array}$ \\
\hline Primary $[\mathrm{n}=286]$ & 11 & $14(9-18)$ \\
\hline Secondary $[\mathrm{n}=233]$ & 13 & $12(7-16)$ \\
\hline
\end{tabular}

Referral by general practitioner (GP) or specialist/gynaecologist:

\begin{tabular}{|c|c|c|}
\hline Category [n] & $\begin{array}{c}\text { Predicted } \\
\text { probability in \% }\end{array}$ & $\begin{array}{c}\text { Observed fraction } \\
\text { in } \% \text { (95\%Cl) }\end{array}$ \\
\hline & & $13(9-16)$ \\
\hline GP [n=485] & 12 & $16(2-29)$ \\
\hline $\begin{array}{c}\text { Specialist/gynaecologist } \\
{[n=34]}\end{array}$ & 6 & \\
\hline
\end{tabular}


1 Supplementary Table SI Calibration of the dynamic prediction model by risk groups.*

2

\section{mean difference max difference number of risk groups}

\begin{tabular}{|c|c|c|c|}
\hline After completion of workup & 1.9 & 5.3 & 9 \\
\hline After 0.5 years EM & 1.7 & 3.4 & 7 \\
\hline After 1 year EM & 1.8 & 3.0 & 5 \\
\hline After 1.5 years EM & 2.9 & 4.0 & 4 \\
\hline Total & 2.1 & 5.3 & 25 \\
\hline
\end{tabular}


8 Supplementary Figure S1 Cumulative chances of natural conception leading to ongoing 9 pregnancy after completion of fertility workup (upper panel) and updated chances of natural conception over the course of 1 year at completion of the fertility workup or 0.5 years, 1 year and 1.5 years thereafter (lower panel) in the validation cohort. Percentages are Kaplan-Meier estimates of the observed fraction of natural conception leading to ongoing pregnancy. Data analysis assumed 1.5 months between registration at the Aberdeen Fertility Clinic and completion of the fertility workup $(n=1261)$.

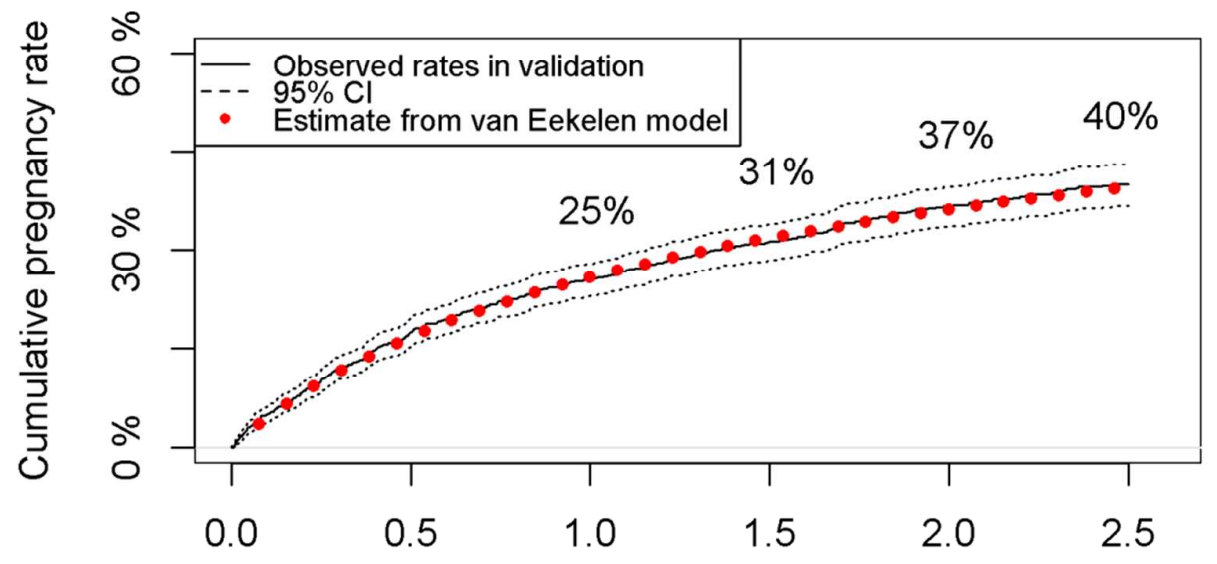

Years since completion of fertility workup

$\begin{array}{llllll}\mathrm{n} \text { in follow up } & 1261 & 965 & 751 & 537 & 412\end{array}$

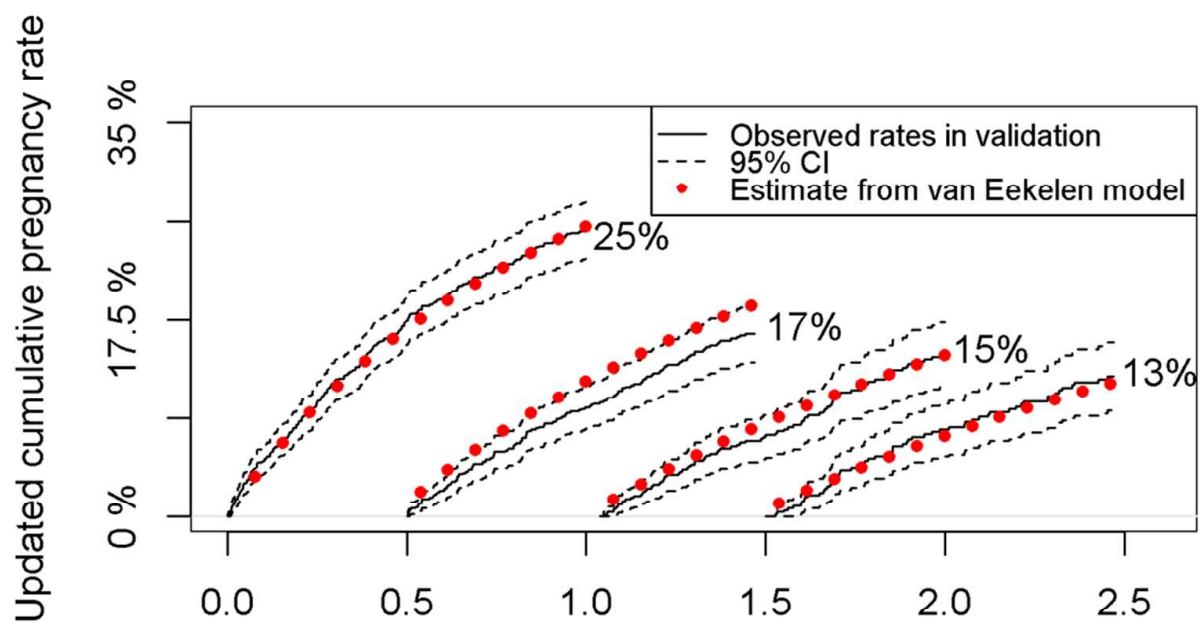

$\begin{array}{llllll}\mathrm{n} \text { in follow up } & 1261 & 965 & 751 & 537 & 412\end{array}$ 
Supplementary Figure S2 Calibration of the predictions of the dynamic prediction model: predicted versus observed 1 year natural conception rates at four fixed time points. Data analysis assumed 1.5 months between registration at the Aberdeen Fertility Clinic and completion of the fertility workup $(n=1261)$.

at completion of the fertility workup ( $n=1261)$

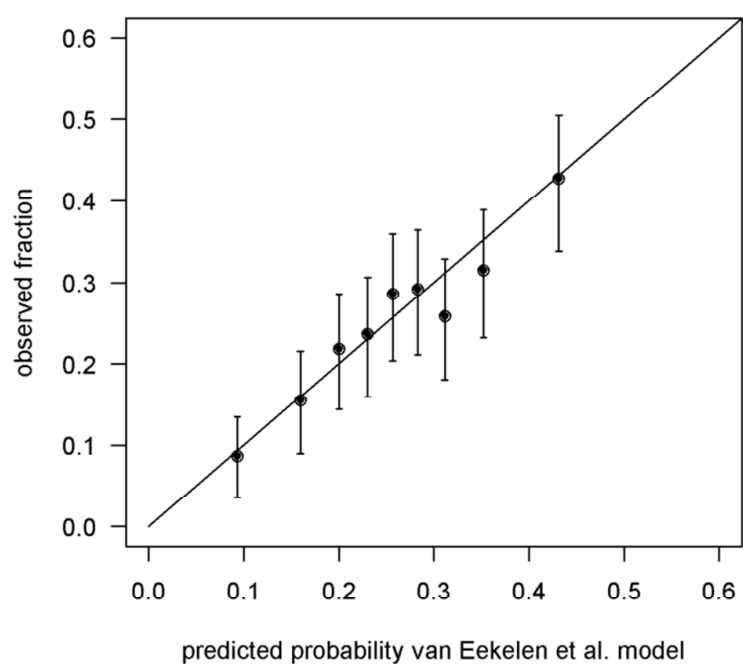

after one year expectant management $(n=733)$

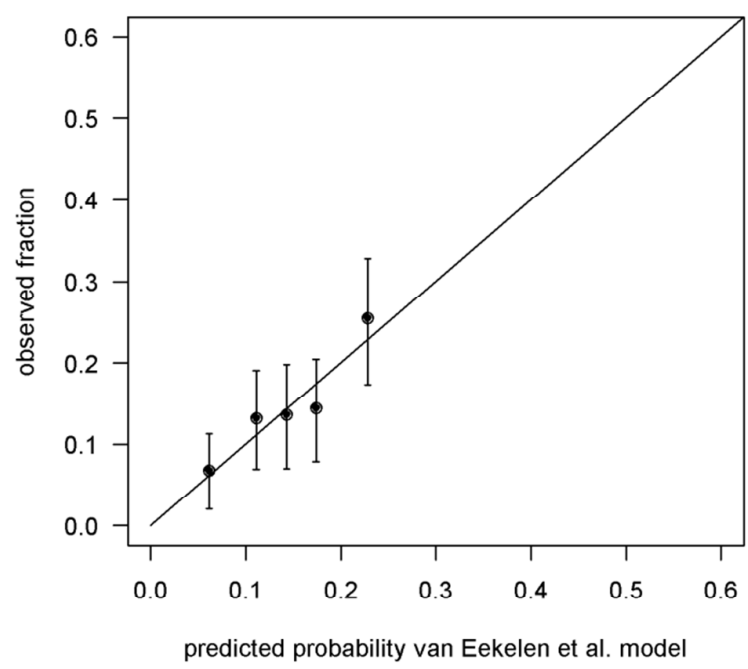

after half a year expectant management ( $n=981)$

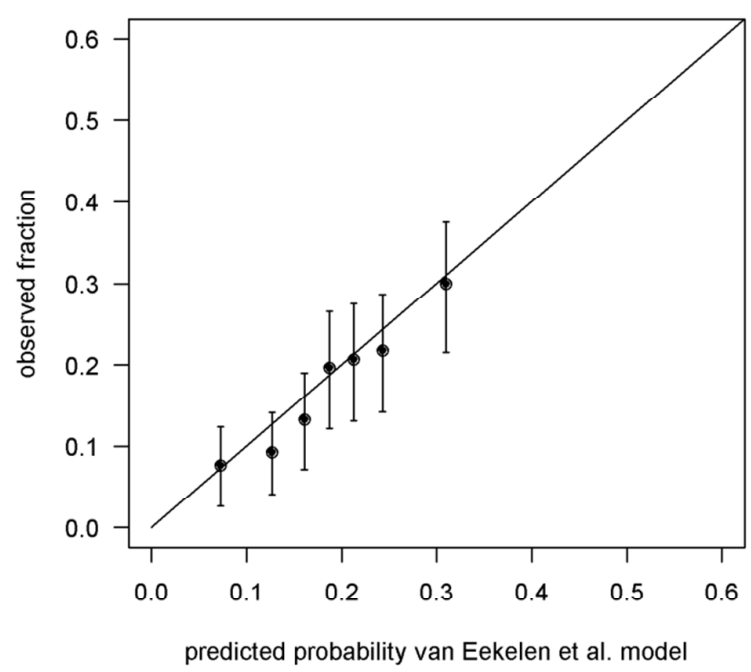

after one and a half years expectant management $(n=540)$

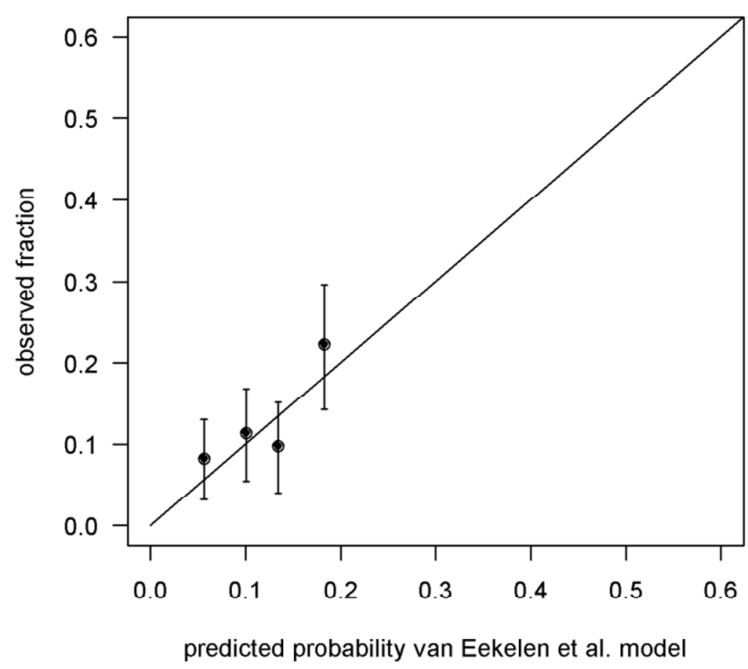

21

22 
23 Supplementary Table SII Calibration of the dynamic prediction model by risk groups.

\section{mean difference max difference number of risk groups}

\begin{tabular}{|c|c|c|c|}
\hline After completion of workup & 3.9 & 11.1 & 8 \\
\hline After half a year EM & 1.9 & 5.8 & 7 \\
\hline After one year EM & 2.6 & 4.3 & 5 \\
\hline After one and a half years EM & 2.3 & 3.3 & 4 \\
\hline Total & 2.7 & 11.1 & 24 \\
\hline
\end{tabular}


Supplementary Figure S3 Cumulative chances of natural conception leading to ongoing pregnancy after completion of fertility workup (upper panel) and updated chances of natural conception over the course of 1 year at completion of the fertility workup or 0.5 years, 1 year and 1.5 years thereafter (lower panel) in the validation cohort. Percentages are Kaplan-Meier estimates of the observed fraction of natural conception leading to ongoing pregnancy. Data analysis assumed 4.5 months between registration at the Aberdeen Fertility Clinic and completion of the fertility workup $(n=1123)$.

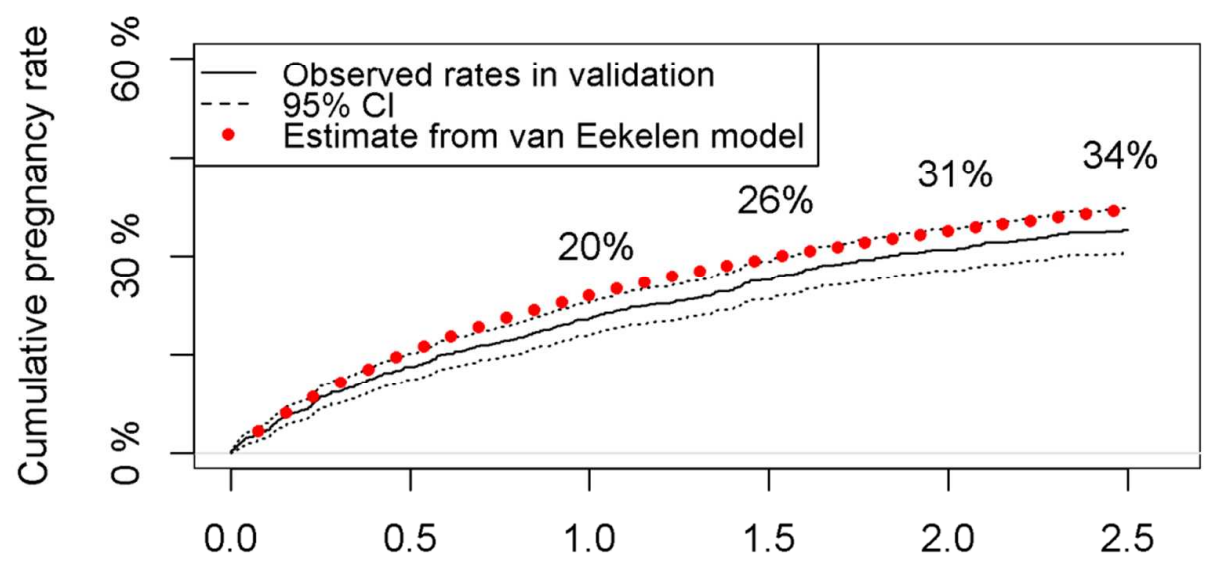

Years since completion of fertility workup

$\begin{array}{llllll}n \text { in follow up } & 1123 & 878 & 646 & 479 & 389\end{array}$

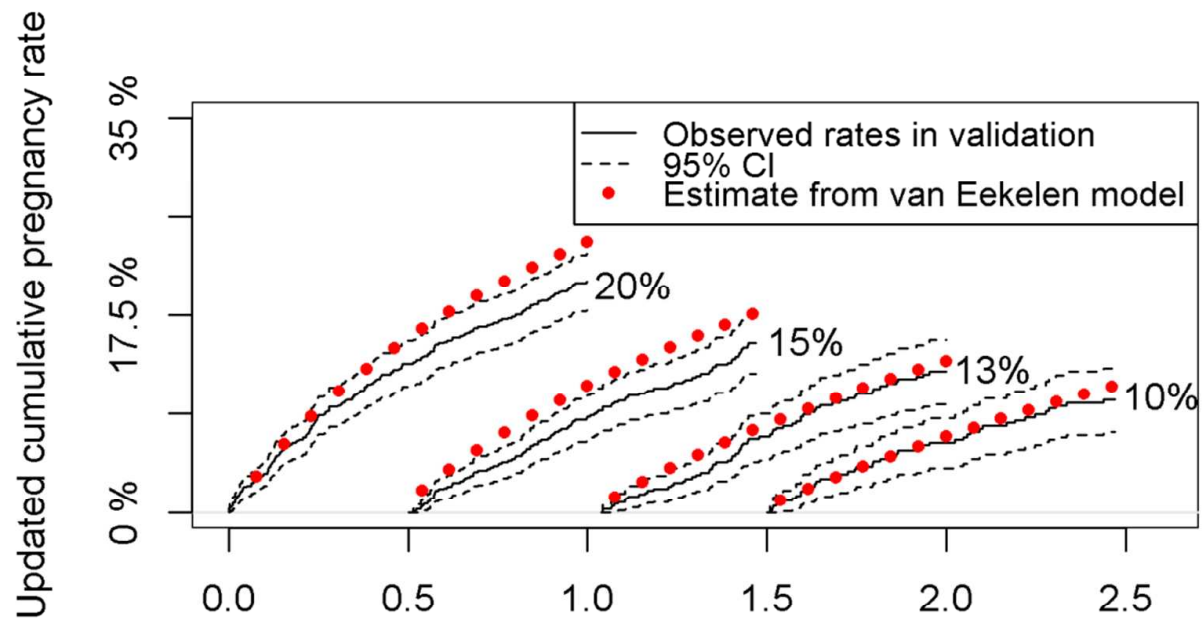

Years since completion of fertility workup

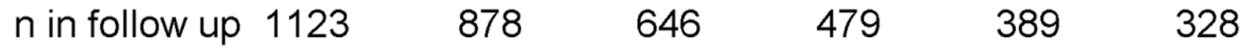


Supplementary Figure S4 Calibration of the predictions of the dynamic prediction model: predicted versus observed 1 year natural conception rates at four fixed time points. Data analysis assumed 4.5 months between registration at the Aberdeen Fertility Clinic and completion of the fertility workup $(n=1123)$.

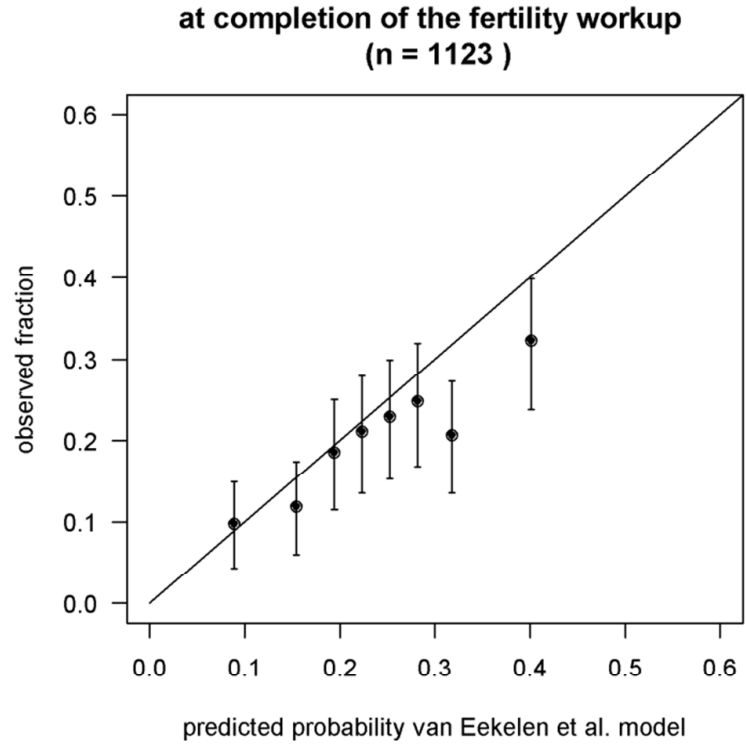

after one year expectant management $(n=635)$

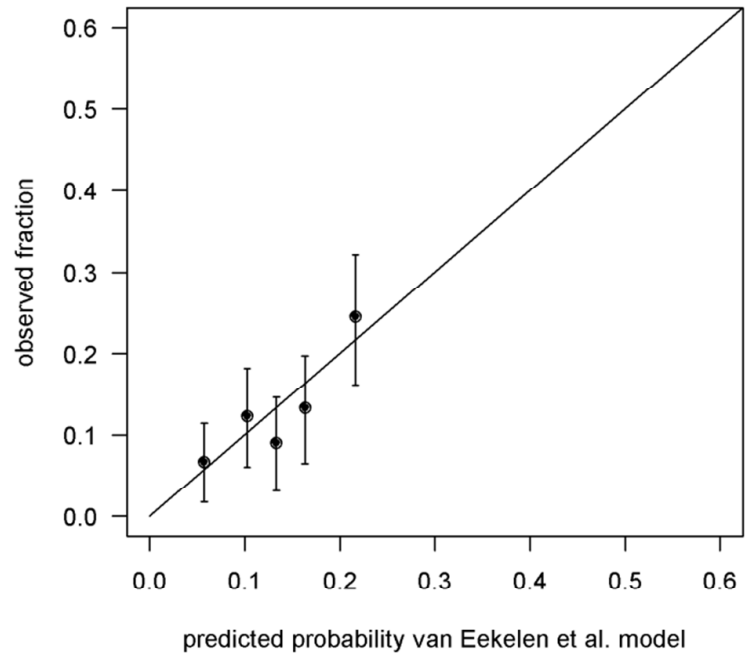

after half a year expectant management ( $n=884$ )

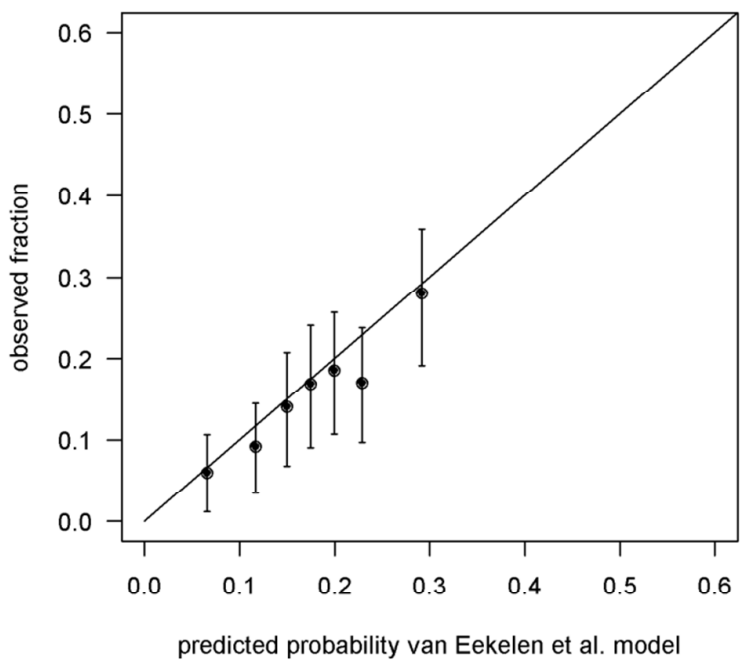

after one and a half years expectant management ( $n=480$ )

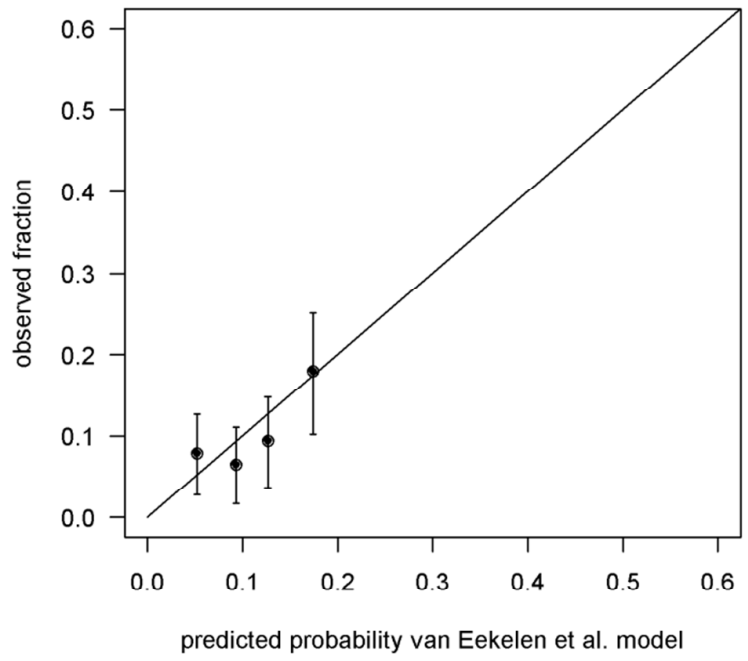

